Note

\section{Comparison of the Enzyme Activities in the Tryptophan-NAD Pathway between the Wistar and Sprague Dawley Strains of Rats}

\author{
Katsumi Shibata, Takashi HayaKawa* \\ and Kazuo IwAI ${ }^{\dagger} *$ \\ Food and Nutrition Laboratories, \\ Teikoku Women's University, Moriguchi, \\ Osaka 570, Japan \\ * Laboratory of Nutritional Chemistry, \\ Department of Food Science and Technology, \\ Faculty of Agriculture, Kyoto University, \\ Kyoto 606, Japan
}

Received November 28, 1985

During experiments on tryptophan-NAD metabolism, when rats were fed a nicotinic acid deficient-diet of an $8.0 \%$ amino acid mixture simulating rice protein supplemented with some limiting amino acids except for tryptophan, ${ }^{1)}$ we have found that there was a difference in growth rate between the rats of the Wistar and Sprague Dawley strains ${ }^{2)}$ and that total amounts of tryptophan metabolites in liver, kidneys, and urine of the rats of the Sprague Dawley strain were higher than those of the rats of the Wistar strain. ${ }^{3)}$ These findings spur us into comparing enzyme activities in the tryptophan-NAD pathway between the two strains of rats.

Six-week-old rats of the Sprague Dawley and Wistar strains were obtained from Clea Japan Inc. The rats of the two strains were separately kept in wire-bottomed cages, and a CE-2 diet (Clea Japan Inc.) and water were supplied ad libitum. The room temperature was $22 \pm 2^{\circ} \mathrm{C}$. The lighting schedule was 06:00 18:00 hr (light) and 18:00 06:00 hr (dark). On the 8th day, the rats (body weight: Sprague Dawley, $214.2 \pm 6.04 \mathrm{~g}(n=6)$; Wistar, $202.5 \pm 7.83 \mathrm{~g}(n=6))$ were intraperitoneally injected with sodium pentobarbital and their livers were removed. Each liver (Sprague Dawley, $8.65 \pm 0.30 \mathrm{~g}$; Wistar, $8.44 \pm 0.19 \mathrm{~g}$ ) was minced and homogenized in five volumes of cold $50 \mathrm{~mm}$ potassium phosphate buffer, $\mathrm{pH} 7.0$, using a Yamato ultradisperser model LK-21. These homogenates were used as enzyme sources for measuring the activities of tryptophan oxygenase (EC 1.13.11.11), kynureninase (EC 3.7.1.3), quinolinate phosphoribosyltransferase (EC 2.4.2.19), nicotinate phosphoribosyltransferase (EC 2.4.2.11), nicotinamide mononucleotide adenylyltransferase (EC 2.7.7.1), NAD synthetase (EC 6.3.5.1), nicotinamide methyltransferase (EC 2.1.1.1), and kynurenine aminotransferase (EC 2.6.1.7). One part of each homogenate was centrifuged at $10,000 \times g$ for $20 \mathrm{~min}$ to measure the activities of 3-hydroxyanthranilic acid oxygenase (EC 1.13.11.6) and aminocarboxymuconate-semialdehyde de-

Table I. Comparison of the Enzyme Activities in the Tryptophan NAD Pathway between THE Livers of The Wistar and Sprague Dawley Strains of Rats

\begin{tabular}{|c|c|c|}
\hline & Wistar & Sprague Dawley \\
\hline & \multicolumn{2}{|c|}{ ( $\mu \mathrm{mol} / \mathrm{hr} / \mathrm{g}$ fresh weight) } \\
\hline Tryptophan oxygenase & $1.57 \pm 0.08^{\mathrm{a}}$ & $2.06 \pm 0.15^{\mathrm{b}}$ \\
\hline Kynureninase & $0.324 \pm 0.012^{\mathrm{a}}$ & $0.259 \pm 0.024^{\mathrm{b}}$ \\
\hline $\begin{array}{l}\text { 3-Hydroxyanthranilic } \\
\text { acid oxygenase }\end{array}$ & $491.38 \pm 36.50^{\mathrm{a}}$ & $693.35 \pm 28.29^{b}$ \\
\hline $\begin{array}{l}\text { Aminocarboxymuconate- } \\
\text { semialdehyde decarboxylase }\end{array}$ & $1.42 \pm 0.20$ & $0.89 \pm 0.15$ \\
\hline $\begin{array}{l}\text { Quinolinate phospho- } \\
\text { ribosyltransferase }\end{array}$ & $0.267 \pm 0.022$ & $0.365 \pm 0.043$ \\
\hline $\begin{array}{l}\text { Nicotinate phospho- } \\
\text { ribosyltransferase }\end{array}$ & $0.049 \pm 0.005^{\mathrm{a}}$ & $0.104 \pm 0.017^{b}$ \\
\hline $\begin{array}{l}\text { Nicotinamide mononucleotide } \\
\text { adenylyltransferase }\end{array}$ & $5.50 \pm 0.15^{\mathrm{a}}$ & $6.57 \pm 0.22^{\mathrm{b}}$ \\
\hline NAD synthetase & $0.88 \pm 0.04$ & $0.91 \pm 0.07$ \\
\hline Nicotinamide methyltransferase & $0.724 \pm 0.030$ & $0.701 \pm 0.014$ \\
\hline Kynurenine aminotransferase & $21.24 \pm 1.69$ & $26.38 \pm 1.76$ \\
\hline
\end{tabular}

Values are mean \pm SE of six rats; means in the same column not sharing a common superscript differ significantly $(p<0.05)$. Significant differences between means having the same variance or different variance when analyzed by the Ftest were evaluated by Student's $t$-test and Welch's test, respectively.

$\dagger$ To whom all correspondence should be addressed. 
carboxylase (EC 4.1.1.45). To measure the enzyme activities we used, for tryptophan oxygenase, the method of Knox et al. $^{4)}$; kynureninase, the method of Takeuchi et al.5); 3-hydroxyanthranilic acid oxygenase, the method of Decker et al. ${ }^{6}$; ; aminocarboxymuconate-semialdehyde decarboxylase, the method of Ichiyama et al. ${ }^{7)}$; quinolinate phosphoribosyltransferase, the method of Iwai and $\mathrm{Taguchi}^{8}$; nicotinate phosphoribosyltransferase, the method of Honjo ${ }^{9}$; nicotinamide mononucleotide adenylyltransferase, the method of Kurokawa et al. ${ }^{10)}$; NAD synthetase, the method of $\mathrm{Yu}$ and Dietrich ${ }^{11)}$; nicotinamide methyltransferase, the method of Cantoni ${ }^{12)}$; and for kynurenine aminotransferase, the method of Tobes and Mason. ${ }^{13)}$

Table I shows the activities of ten enzymes that are involved in tryptophan-NAD metabolism in the livers of the Wistar and Sprague Dawley strains. The activities of tryptophan oxygenase, 3-hydroxyanthranilic acid oxygenase, and nicotinate phosphoribosyltransferase in the liver of the Sprague Dawley strain were significantly higher than those of the Wistar strain. The activities of NAD synthetase, nicotinamide methyltransferase, and kynurenine aminotransferase were almost the same between the two strains. The activity of quinolinate phosphoribosyltransferase tended to be higher ( 1.4 fold) in the Sprague Dawley strain than the Wistar strain, though it was not significantly different. The activity of aminocarboxymuconate-semialdehyde decarboxylase tended to be lower ( 0.6 fold) in the Sprague Dawley strain than the Wistar strain, though it was not significantly different. The lower activity of aminocarboxymuconatesemialdehyde decarboxylase means that quinolinic acid formation from tryptophan is higher in the Sprague Dawley strain than the Wistar strain. Generally speaking, the higher enzyme activities of the tryptophan-NAD pathway in the livers of the Sprague Dawley strain were more in favor of NAD formation from tryptophan than those of the Wistar strain. The higher production of the tryptophan metabolites and the higher growth rate of the Sprague Dawley strain than of the Wistar strain ${ }^{2)}$ was due to the higher enzyme activities of the tryptophan-NAD pathway in the Sprague Dawley strain. Therefore, the Sprague Dawley strain of rats has greater resistance to a low nicotinic acid diet than the Wistar strain. The strains of rats should be considered when referring to the results from different papers.

Acknowledgment. The authors express their sincere appreciation to Mrs. Kazumi Tanaka for technical assistance.

\section{REFERENCES}

1) A. Yoshida, Agric. Biol. Chem., 35, 1943 (1971).

2) K. Shibata, K. Motooka and K. Murata, The Bulletin of Teikoku-Gakuen, No. 6, 1 (1980).

3) K. Shibata, K. Motooka and K. Murata, J. Nutr. Sci. Vitamonil., 28, 11 (1982).

4) W. E. Knox, A. Yip and L. Reshef, "Methods in Enzymology," Vol. 17A, ed. by H. Tabor and C. W. Tabor, Academic Press Inc., New York, 1970, p. 415.

5) F. Takeuchi, H. Otsuka and Y. Shibata, J. Biochem., 88, 987 (1980).

6) R. H. Decker, H. H. Kang, F. R. Leach and L. M. Henderson, J. Biol. Chem., 236, 3076 (1961).

7) A. Ichiyama, S. Nakamura, H. Kawai, T. Honjo, Y. Nishizuka, O. Hayaishi and S. Senoh, J. Biol. Chem., 240, 740 (1965).

8) K. Iwai and H. Taguchi, J. Nutr. Sci. Vitaminol., 19, 491 (1973).

9) T. Honjo, "Methods in Enzymology," Vol. 18B, ed. by D. B. McCormick and L. D. Wright, Academic Press Inc., New York, 1971, p. 123.

10) M. Kurokawa, T. Kato and H. Inamura, Proc. Jpn. Acad., 42, 1217 (1966).

11) C. K. Yu and L. S. Dietrich, J. Biol. Chem., 247, 4794 (1972).

12) G. L. Cantoni, J. Biol. Chem., 189, 203 (1951).

13) M. C. Tobes and M. Mason, Biochem. Biophys. Res. Commun., 62, 390 (1975). 